\title{
All Cops Are Trusted? How Context and Time Shape Immigrants' Trust in the Police in Europe
}

\author{
Christian S. Czymara (Goethe University Frankfurt, Germany) \\ $\&$ \\ Jeffrey Mitchell (Umeå University, Sweden)
}

Published in Ethnic and Racial Studies, available at: https://doi.org/10.1080/01419870.2022.2060711

\begin{abstract}
The relationship between police and ethnic minorities has been the subject of increasing interest in many Western societies in recent years. We examine first-generation immigrants' trust in the police in Europe from a comparative and longitudinal perspective. Based on roughly 20,000 immigrants observed in 22 countries over 13 years in the European Social Survey, results show that initially high levels of trust in the police among immigrants tend to erode with the length of their stay in the host country. We show that two simultaneous processes drive this pattern: a fading reference effect (downward assimilation) and an increasing discrimination effect. Crossnational comparisons show that, on average, immigrants in countries with more police trust the police less. However, there is no effect of police size within countries, mostly because police numbers hardly change over time. We discuss implications for future research and policy development based on our findings.
\end{abstract}

Keywords: Immigration; Police; Trust; Europe; Discrimination; Integration 


\section{Introduction}

The killing of George Floyd by a police officer in the US in May 2020 led to nationwide protests and debates about police violence against ethnic minorities, which quickly spilled over into various other Western countries. Research from the US reports that minorities' trust in police is relatively low (Tyler 2005; Weitzer and Tuch 2005). In the European context, immigrants and their children have been the focal interest of research into legitimacy of and trust in the police amongst minority groups ${ }^{1}$. However, Röder and Mühlau (2012) show that trust in the police among first-generation immigrants is actually higher than trust levels of natives, but this is not true for second-generation immigrants. It thus appears that, first, explaining immigrants' trust in the police in Europe is not identical to explaining racial differences in police trust in the US. Second, immigrants' trust in the police in European societies seems to erode over generations. However, to what degree this is true over an immigrant's individual life course is an open question. Moreover, we know little about the drivers of this loss of trust of immigrants over time.

To better understand the dynamic of trust in the police amongst immigrants we focus on actual, i.e. first-generation, immigrants in Europe. We argue that there are two mechanisms that explain immigrants' trust in the police: (1) discrimination experiences in policing in the host country and (2) references to the police in the country of origin. Both should be stronger for immigrants from non-Western countries. However, while the former should have a negative effect on trust, the effect of the latter should be positive. Following Superti and Gidron (2021) in their analysis of immigrants' attitudes in Israel, we synthesize both mechanisms in a crossnational analysis and argue that time is an important moderator: reference to the origin country should mainly be important for recent immigrants, and the importance of this reference should vanish as immigrants spend more time in the host country. At the same time, encounters with the police and the justice system, many of which might be the product of (perceived) discrimination, can accumulate over time. Such encounters are more likely the larger the size of the police force in the destination country. Both mechanisms point toward the same direction: a weakening positive effect of reference and an intensifying negative effect of discrimination experiences, both lead to eroding trust over time. However, these should vary with immigrant characteristics on the individual- and the country-level.

We test these considerations based on cross-national survey data over 13 years, contained in the third to the ninth waves of the European Social Survey, combined with data from Eurostat and other sources. On the individual level, we show that recent immigrants indeed tend to exhibit relatively high levels of trust in the police in the country of destination. This is especially the case if they originate from a country with lower adherence to the rule of law and immigrate to a country with higher adherence to the rule of law. However, this association is practically zero for immigrants who changed their country of residence a long time ago (20 years or more), indicating that reference frames diminish over the life course. Simultaneously to this process, our results show that the relationship between perceived discrimination and trust in the police is stronger for those who immigrated a long time ago compared to those who immigrated recently. We interpret this evidence as an indicator of the cumulative nature of discrimination experiences the more time an immigrant has spent in a destination country. Results on the country level reveal that immigrants' trust is lower in countries with larger police forces. However, as national police force size hardly changes over time, we do not observe a significant within effect of police numbers based on country-fixed effects models.

\section{Drivers of immigrants' trust in the police: Institutional improvement and discrimination experiences}

Public trust in institutions, including in the police, is often linked to the quality of government, as the expectation of institutions to be capable and to act in the public interest is key to trust in institutions (Kääriäinen 2007). Applied to immigrants, previous research into the predictors of trust in police points to two important factors:

\footnotetext{
${ }^{1}$ This is likely because many immigrants, especially those who have recently migrated and those from nonWestern countries, are members of ethnic minority groups. However, there are of course non-immigrant ethnic minority groups in Europe, for example the Roma, whose trust in the police is important.
} 
institutional differences between their origin and destination countries, and experiences of discrimination after arrival in their host country (Röder and Mühlau 2012).

Immigration into Europe in the post-war era has been complex and diverse, occurring in waves that have included immigrants from other European countries as well as from outside the continent (Van Mole and de Valk 2016). The institutional differences between the origins and destinations of these people are subject to significant variation. From a global perspective, political institutions in general and the judiciary in particular perform relatively well in most European countries. Thus, people who migrate to Europe, or to a country with better institutions within Europe, should trust the police more, given their past experiences. We will refer to migrating from an origin country with lower adherence to the rule of law to a destination country with higher adherence to the rule of law as an institutional improvement. Trust in the police should be higher for immigrants who have experienced institutional improvement compared to immigrants whose destinations and origins are more similar (or in case of institutional deterioration, see for example Dalberg and Linde, 2018). Institutional improvement is likely to have a positive impact on trust in the police due to the expectation that the police are going to distribute justice more fairly than in immigrants' countries of origin (Röder and Mühlau 2012; Superti and Gidron 2021). We hypothesize that the state of institutions in the origin country functions as a reference frame for immigrants:

- Hypothesis 1: Immigrants who have moved from countries with lower rule of law to countries with higher rule of law will trust the police more. (Institutional Improvement-Hypothesis)

Röder and Mühlau (2012) also note that the difference is more pronounced for first-generation than for secondgeneration immigrants. Their findings speak to the complicated relationship between the cultural and experiential influences of trust that are highlighted by the immigration experience (Dinesen 2012). However, the category of "second-generation immigrant" is conceptually debatable, since these individuals are children of immigrants but do not have their own migration experiences. The contrast between origin to host societies should be even more relevant for people who themselves migrated between countries. Moreover, comparing people within the group of first-generation immigrants results in a clearer design than comparing between firstand second-generation immigrants, two groups that are arguably more different. For example, immigrants might have increased expectations of procedural justice in host countries due to institutional improvement compared to their birth country. The children of immigrants' expectations, however, are likely tempered by the realities of being socialized in the host context. Superti and Gidron (2021) explored this idea and found that people who immigrated to Israel at a young age had lower levels of trust in the police, possibly because they were not old enough to make the comparison to their home country. However, it is also possible that migration experiences fade with time. Considering this possibility cross-nationally, we hypothesize that the relationship postulated in $\mathrm{H} 1$ mainly exists for those who migrated recently, and should be substantively weaker for individuals whose migration took place a long time ago:

- Hypothesis 2: The positive effect of institutional improvement is strong for those who migrated recently, but weak for those who migrated a long time ago. (Fading Reference-Hypothesis)

The cultural explanation argues that trust is learned during the socialization process, while people are young, and is relatively stable over time in adults (Dinesen 2012). In this case, the difference in trust found between first- and second-generation immigrants would be explained by different socialization contexts as described above. On the other hand, the experiential explanation argues trust is subject to change in relation to experiences that people have in their lives. In this case, differences in trust in the police between natives and immigrants described in other studies should decrease over time, as immigrants' opportunities for experiences with the police accumulate and their trust in police decreases. A convergence of this type is seen in other types of attitudes as well, including on the issue of immigration itself (Just and Anderson 2015), but attitude convergence can also be context-dependent, with immigrants and natives becoming more alike in some countries than in others (Czymara and Eisentraut 2020). Immigrants' trust in police often begins at a higher level compared to natives. The experiential hypothesis regarding the convergence of trust levels between natives and immigrants would argue that their experiences are likely different. While the experiences of all immigrant groups are presumed to 
be different from those of natives, they are likely to be very different for immigrants subject to discrimination because they belong to visible minority groups. In other words, a drop in trust may likely be related to instances in which immigrants experience discrimination. This could occur either by immigrants generalizing their discrimination experiences with the civilian (non-police) population, or through direct interactions with the police themselves. Discrimination experiences are often more impactful for immigrants when their expectation of equal treatment is higher, and therefore the violation of this expectation is greater (Ziller 2017). Unfortunately, measuring discrimination through racial profiling is difficult since discrepancies in stops, arrests, and convictions between groups are themselves subject to endogeneity (Pierson et al. 2020), which complicates efforts to understand how discrimination on the basis of ethnicity or immigration status might affect trust (Resh 2018; Yeager et al. 2017). As Bradford and Jackson (2017) show in an analysis of a special round on policing in the fifth round of the ESS; immigrants report having interactions with the police at similar rates to natives, but they were more likely to evaluate those interactions as unsatisfactory. Both these unsatisfactory interactions with police, as well as experiences of discrimination generally, were associated with reduced trust amongst immigrants. We build on these findings and test the relationship between discrimination and trust in the police longitudinally among individuals in different countries and time contexts. As more time in a destination country allows for more opportunities for negative contact (Ziller and Spörlein 2020), this implies that experiences of discrimination are likely to increase. As a result of such accumulated discrimination experiences, the link between trust in police and feeling discriminated against should become stronger over time:

- Hypothesis 3: The effect of discrimination on trust in the host country's police should become stronger with the length of stay in the host country. (Discrimination Accumulation-Hypothesis)

\section{Police force size and immigrants' trust in the police in Europe}

Cross-national differences in institutional trust are often explained by the quality of the institutions themselves (Mewes et al. 2021; Mishler and Rose 2001; Rothstein and Stolle 2008; Schnaudt et al. 2021), which includes both instiutitional capacity and levels of adherence to the rule of law. The importance of (perceived) procedural justice in people's evaluations of the police is shown by a decrease in trust in the police in France after an incident of excessive use of force against a black man that led to riots in 2017 (Nägel and Lutter 2021). One way to measure institutional capacity cross-nationally is to use the size of the police force. Somewhat paradoxically, research indicates a negative correlation, where countries with high levels of police per capita on average display lower levels of trust in the police (Nägel and Vera 2021; Kääriäinen 2016). One explanation for this is that having more police does not seem to lead to lower crime rates (Lee et. al 2016) or changes in perceptions of police effectiveness (Schaap 2016). Moreover, the police force tends to be larger in countries that are more corrupt (Nägel and Vera 2021). Such countries violate justice norms and undermine legitimacy in the institution of the police (Schaap 2020). These aspects should also shape immigrants' trust in the police in European host societies:

- Hypothesis 4: A larger police force is associated with less trust in the police among immigrants. (Police Force Size-Hypothesis)

We argued above that immigrants' discrimination experiences are likely to erode the belief that the police are trustworthy. Negative encounters with police can undermine immigrants' expectations of procedural justice. If there are negative encounters with police, the chances of such negative contact should increase with a larger police force. This should be especially relevant for immigrants that have spent much time in a context with a large police force, because more time also implies more opportunities for negative contact (Ziller and Spörlein 2020). Police force size might, thus, continue to be an important factor for trust in the police, if immigrants spend much time in such contexts. This means that the time since immigration should moderate the relationship between police force size and trust for immigrants. We hypothesize that the relationship between police force size and trust varies with the time since migration:

- Hypothesis 5: The link between national police force size and trust will be stronger for immigrants who arrived in their destination country a long time ago. (Police Force Size Interaction-Hypothesis) 
Note that Hypothesis 5 relies on the assumption that there is negative contact with police. Ultimately, we cannot test this directly, as there is no reliable measure of negative contact with the police across countries. Given prior evidence (Bradford and Jackson 2018; Tyler 2005), however, it seems reasonable that policing implies some negative contact and, consequently, that more time with more police implies more negative contact than less time with fewer police. The larger the share of negative contact in all contact with police, the larger the interaction effect postulated in Hypothesis 5 should be. We will address the plausibility of this assumption further in the discussion.

\section{Data}

We pool data from waves three to nine $^{2}$ of the European Social Survey (ESS), ranging from 2005/06 to 2018/19. ${ }^{3}$ We focus on immigrants, who we define as individuals who were not born in their current country of residence.

We use the following item to measure trust in police:

"Using this card, please tell me on a score of 0-10 how much you personally trust each of the institutions I read out. 0 means you do not trust an institution at all, and 10 means you have complete trust." Followed by "The police".

First, we are interested in institutional improvement, defined as the contrast between institutions of each immigrant's origin country and the ones in their host country. To this end, we draw upon the data from the Freedom House Rule of Law measure, obtained through the Quality of Government Institute. This Rule of Law measure consists of (1) existence of an independent judiciary, (2) due process prevailing in civil and criminal matters, (3) protection from the illegitimate use of physical force, and (4) the guarantee of equal treatment of various segments of the population. ${ }^{4}$ The variable has a theoretical range from 0 (worst) to 16 (best) ${ }^{5}$. We used information on the Rule of Law for immigrants' origin and destination countries. Based on both country values, we calculate the difference between origin and destination country for each person. Thus, positive values imply institutional improvement, negative values imply institutional deterioration, and 0 would imply migrating between two countries with exactly the same level of Rule of Law.

Second, we want to test effects of discrimination. To measure perceived discrimination, we draw upon the following binary item: "Would you describe yourself as being a member of a group that is discriminated against in this country?" As an alternative approach, we use the item "Do you belong to a minority ethnic group in [country]?".

To test whether effects of institutional improvement and discrimination experiences vary with immigrants' length of stay in their host country, we use a harmonized variable with five categories that measure time since migration: "Within the last year", "1-5 years ago", "6-10 years ago", "11-20 years ago", and "More than 20 years ago".

Because socio-economic variables potentially confound our relationships of interest, we control for education, income satisfaction, gender, and a quadratic age effect. While income satisfaction and time since migration have categorical character, models show almost perfectly linear effects of both variables. Thus, we add them as continuous predictors, which does not influence our conclusions. We use the APIs provided by Cimentada (2019), Kainu (2020), and Lahti et al. (2017) for data import.

\footnotetext{
${ }^{2}$ We dropped the first two ESS waves because the Rule of Law index is only available from 2005 on.

${ }^{3}$ We use the following editions: round 3 : 3.7 ; round 4 : 4.5 ; round 5 : 3.4 ; round $6: 2.4$; round 7 : 2.2 ; round 8 : 2.2; round 9: 3.1

${ }^{4}$ https://freedomhouse.org/reports/freedom-world/freedom-world-research-methodology

${ }^{5}$ An alternative would be the Corruption Perception Index (CPI), which is used by, for example, Nägel and Vera (2021). However, we explicitly chose the Rule of Law measure because, in contrast to the CPI, it is quite close to the concept of procedural justice, as its four components are directly connected to policing and the justice system.
} 
Regarding cross-national differences, our main interest lies in the national size of the police force. We draw upon data from Eurostat to measure the total number of police officers per 100,000 inhabitants in a country each year. There are several national characteristics that may confound our effect of interest. First, governments may increase police force size in response to high crime rates, and higher crime is likely associated with lower trust in the police. Measuring crime across countries and across time is notoriously difficult, however, as countries differ in legislation and reporting. Similar to previous research (e. g., Nägel and Vera 2021), we use homicides per 100,000 inhabitants as a proxy for a country's overall level of crime. While homicide is a very severe crime, it is clearly defined and reported to the police in almost all instances. Second, Nägel and Vera (2021) argue that the negative correlation between national police force size and trust in police is actually caused by corrupt and malfunctioning institutions. To account for this possibility, we control the host country's Freedom House Rule of Law score described above. Third, police force size and trust might be influenced by a country's wealth, which we control for using GDP per 100,000 inhabitants. Finally, the presence of immigrants might also influence trust levels and police force size. Thus, we also control for the number of immigrants in a country at a given point in time relative to the overall population. We take information on homicides, GDP, and immigration from Eurostat. ${ }^{6}$

\section{Method}

We use random effects modeling to decompose the variance of trust in the police into three parts: between respondents, within countries over time, and between countries (Fairbrother 2014). We estimate three-level hierarchical linear models to account for this data structure where individuals are nested in country-waves, which are nested in countries (Schmidt-Catran and Fairbrother 2016). For each time-varying country variable, we include a demeaned version and its mean, obtained through Lüdecke et al. (2020). The demeaned variables result in within effects (WE), which are based purely on variance within countries over time. WE thereby offer the huge benefit of controlling for all national characteristics that are practically time-constant, such as regime types or histories. The mean variables yield between effects (BE), which are based only on time-stable differences across countries (Fairbrother 2014). To get interpretable estimates for the WE, we do not add wave dummies to our model (Kropko and Kubinec 2020). We use the R Imer command from Bates et al. (2015) to estimate our models and the packages of Lüdecke (2019) to plot the results.

For the cross-level interaction between national police numbers and individual time since migration, we employ the estimator developed by Giesselmann and Schmidt-Catran (2019). That is, we add two ancillary interaction terms: the interaction of demeaned police numbers with mean time since migration, and the interaction of mean police numbers with time since migration. These additional interaction terms absorb all potential between country variance that could plague the WE interaction. In this way, the main interaction of interest (demeaned police numbers and time since migration) provides a genuine within estimator. For all crosslevel interactions, we add random slopes for the individual-level moderator (Heisig and Schaeffer 2019).

\section{Sample of analysis}

Our analysis includes all members of the European Union or the European Free Trade Association that were part of the European Social Survey between waves 3 to 9. Since the ESS does not oversample immigrants, some countries include rather small numbers of respondents. This means that only a few individuals drive the average trust values in these cases. For example, there are only nine immigrants in Poland in the eighth ESS wave after list-wise deletion. One might doubt whether such a small number of individuals can capture national levels in immigrant trust in the police well. To lower the impact of single, potentially idiosyncratic, individuals, we drop country-waves that exhibit fewer than 50 interviews (after list-wise deletion). This results in 19,147 immigrants observed in 110 country-waves from 22 different countries. However, keeping those respondents in the data or removing country-waves with less than 100 observations does not change our conclusions. For the final list of respondents and countries, see Table 1. Table 2 shows descriptive statistics averaged over countries and waves.

\footnotetext{
${ }^{6}$ Code is available at https://dx.doi.org/10.17605/OSF.IO/BWXEA
} 
Table 1: Number of observations per country and wave

\begin{tabular}{lrrrrrrr} 
& \multicolumn{7}{c}{ Ess wave } \\
AT & 3 & 4 & 5 & 6 & 7 & 8 & 9 \\
\cline { 2 - 7 } BE & 121 & & & & 181 & 181 & 246 \\
CH & 144 & & 180 & 245 & 219 & 242 & 252 \\
CY & 301 & 375 & 309 & 291 & 342 & 370 & 348 \\
DE & 192 & 195 & 247 & 268 & 275 & 263 & 268 \\
DK & 70 & 84 & 92 & 91 & 106 & & 87 \\
EE & 265 & 234 & & 322 & 361 & 274 & 246 \\
ES & 135 & 220 & 172 & 204 & 140 & 181 & 184 \\
FI & & 53 & 63 & 92 & 93 & & \\
FR & 173 & 150 & 144 & 197 & 199 & 195 & 215 \\
GB & & 222 & 214 & 219 & 155 & 124 & \\
GR & & 107 & 237 & & & & \\
HR & & 100 & 136 & & & & 167 \\
IE & 190 & 277 & 363 & 351 & 267 & & \\
IT & & & & 51 & & 123 & \\
LT & & & 67 & & 52 & & \\
LV & 173 & 230 & & & & & 94 \\
NL & 150 & 151 & & & 147 & 111 & 145 \\
NO & 103 & 103 & 147 & 101 & 99 & & \\
PT & 118 & 124 & 126 & 105 & 87 & 90 & 116 \\
SE & 193 & 196 & 154 & 199 & 206 & 162 & \\
SI & 77 & 87 & 86 & 101 & 90 & 111 & 129
\end{tabular}

Table 2: Global descriptives

\begin{tabular}{lrrrr} 
& \multicolumn{2}{c}{$\begin{array}{c}\text { Standard } \\
\text { deviation }\end{array}$} & Min & Max \\
\cline { 2 - 5 } Mean & & & & \\
Trust in police & 6,52 & 2,48 & 0 & 10 \\
Country-level variables & & & & \\
Police size (within) & 0 & 29,06 & $-92,28$ & 90,34 \\
Police size (between) & 301 & 90,39 & 147,03 & 624,37 \\
GDP/c (within) & 0 & 1212,07 & $-3356,53$ & 3142,27 \\
GDP/c (between) & 33512,26 & 14863,54 & 10032,89 & 67290,14 \\
Rule of law (within) & 0 & 0,4 & $-1,62$ & 0,89 \\
Rule of law (between) & 14,52 & 1,03 & 10,75 & 16 \\
Crime (within) & 0 & 0,58 & $-2,26$ & 2,6 \\
Crime (between) & 1,41 & 1,22 & 0,59 & 5,93 \\
Immigration (within) & 0 & 298,61 & $-534,2$ & 1580,32 \\
Immigration (between) & 1057,36 & 525,63 & 259,73 & 2414,14 \\
Individual-level variables & & & & \\
Institutional improvement & 5,3 & 4,69 & -5 & 16 \\
Time since migration & & & & \\
Within last year & 0,01 & 0,1 & 0 & 1 \\
1-5 years ago & 0,12 & 0,33 & 0 & 1 \\
6-10 years ago & 0,13 & 0,34 & 0 & 1
\end{tabular}




\begin{tabular}{|c|c|c|c|c|}
\hline $11-20$ years ago & 0,21 & 0,41 & 0 & 1 \\
\hline More than 20 years ago & 0,53 & 0,5 & 0 & 1 \\
\hline \multicolumn{5}{|l|}{ Member of discriminated } \\
\hline group (vs. not discriminated) & 1,16 & 0,37 & 1 & 2 \\
\hline $\begin{array}{l}\text { Member of minority group } \\
\text { (vs. not minority) }\end{array}$ & 1,27 & 0,45 & 1 & 2 \\
\hline \multicolumn{4}{|l|}{ Education } & \\
\hline High (>= ISCED 5) & 0,24 & 0,43 & 0 & 1 \\
\hline Low $(<=$ ISCED 2) & 0,34 & 0,47 & 0 & 1 \\
\hline Medium high (ISCED 4) & 0,12 & 0,33 & 0 & 1 \\
\hline Medium low (ISCED 3) & 0,3 & 0,46 & 0 & 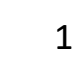 \\
\hline \multicolumn{4}{|l|}{ Income satisfaction } & \\
\hline Living comfortably & 0,28 & 0,45 & 0 & 1 \\
\hline Coping & 0,43 & 0,49 & 0 & 1 \\
\hline Difficult & 0,21 & 0,41 & 0 & 1 \\
\hline Very difficult & 0,08 & 0,27 & 0 & 1 \\
\hline Gender & 1,54 & 0,5 & 1 & 2 \\
\hline Age & 47,01 & 16,97 & 15 & \\
\hline
\end{tabular}

\section{Results}

Descriptive overview on immigrants' trust and police force size

Immigrants' trust levels in the police in Europe vary considerably by country, as Figure 1 shows. On average, immigrants trust the police most in Finland, with a mean of 7.8 out of 10, and least in Lithuania, with a mean of merely 4.7. As a general pattern, immigrants in countries in Northern or Central Europe, such as Finland, Denmark, or Switzerland, tend to have more trust in police, while immigrants in countries in Southern or Eastern Europe, for example Lithuania, Latvia, or Greece, tend to have lower trust in police. This correlates strongly negatively with the national size of the police $(r=-0.69)$. As an example, Finland, where immigrants trust the police most, has the smallest police force in our data, with about 147 officers per 100,000 inhabitants. This mirrors findings based on the overall populations in Europe (Nägel and Vera 2021) and indicates that, on average, immigrants residing in countries with fewer police have higher levels of trust in the police. 
Figure 1: Cross-sectional correlation between immigrants' trust in police and police size

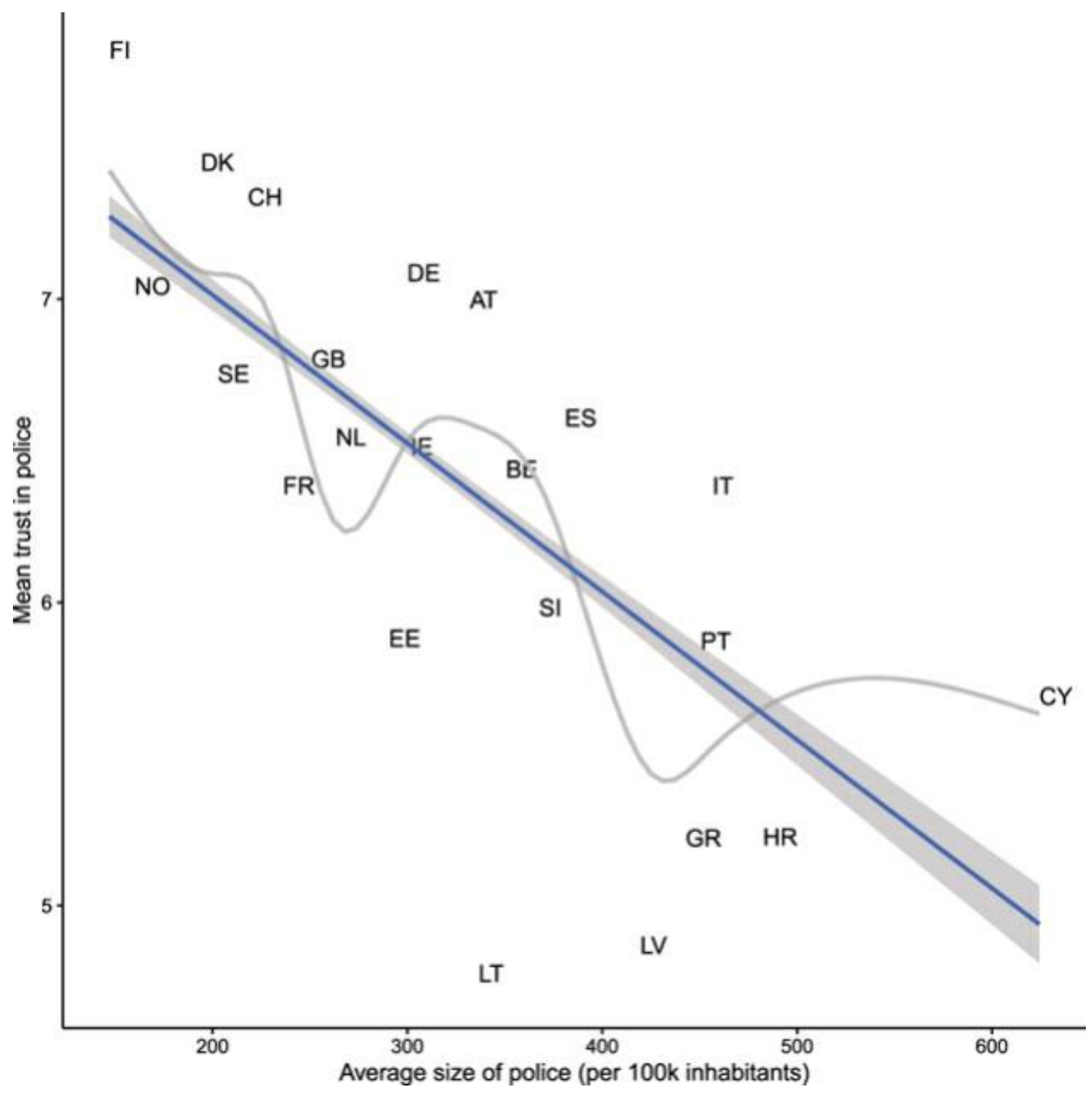

Examining trends within countries over time leads to additional insights. Although trajectories differ for individual countries, there is an overall positive trend over time, as Figure 2 shows. Averaged over all countries, the mean values increased from 6.1 in wave 3 to 7.0 in wave 9 (although one might be cautious with this comparison as not all countries are included in all waves). There is no country where trust levels fell monotonically. This implies that immigrants' trust in the police in Europe has increased in recent years, which is also true for countries that have relatively low levels of police trust. 
Figure 2: Time trends in immigrants' trust in the police in Europe

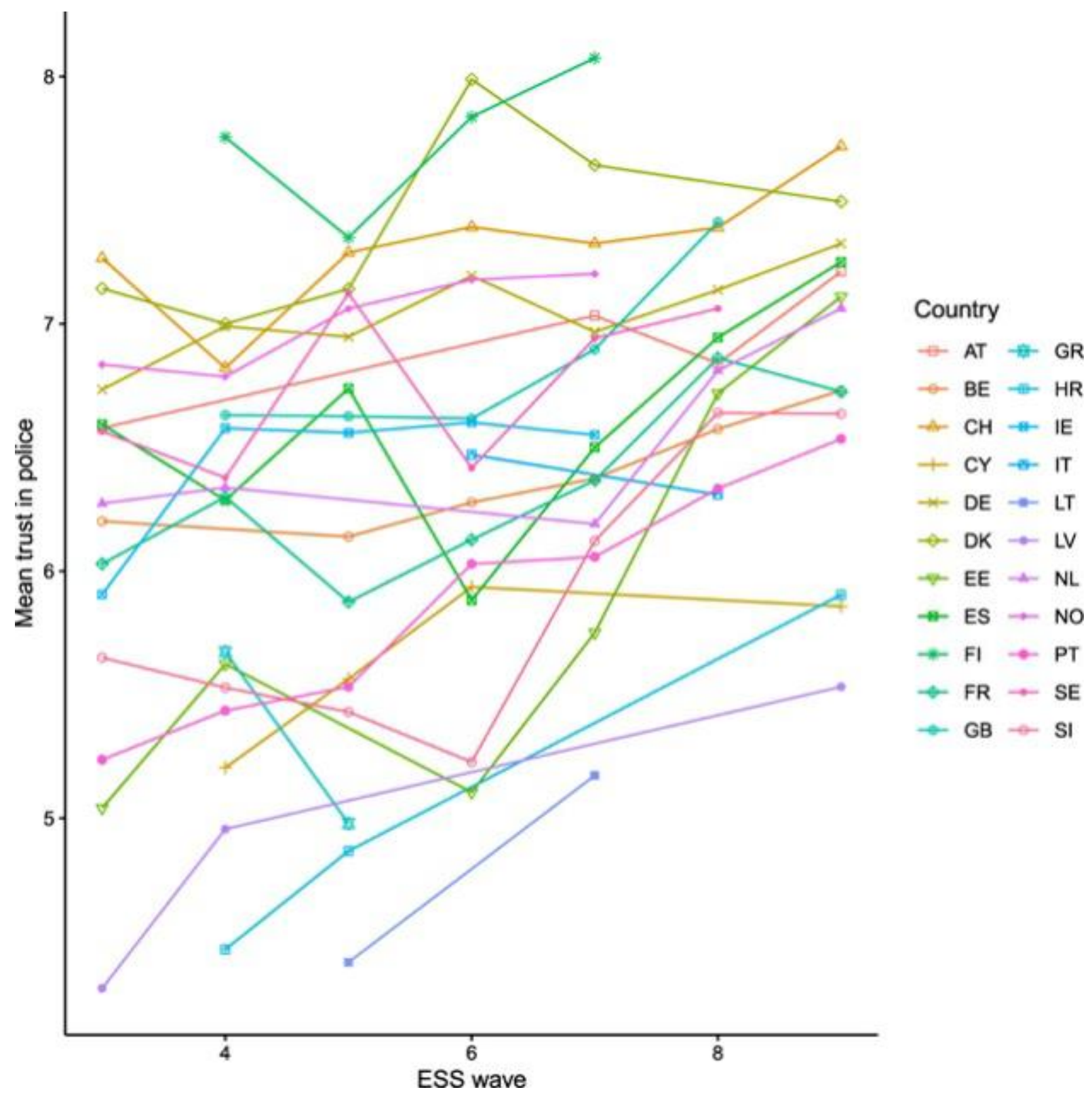

Interestingly, this does not reflect the trends in police numbers over time, which were rather stable for most countries (Figure 3). There are some changes, e.g. an increase for France from waves 6 to 7, and in Estonia from waves 4 to 6 . Overall, however, police numbers are remarkably time-invariant for most countries we examine. The descriptive evidence of Figures 2 and 3 implies that public trust in the police does not follow the same trend as national police force size. While the former has a slight upward trend in the aggregate, the latter is mostly stable. Figures A1 and A2, and Table A1 in the appendix, show trends of our country-level control variables over time. 
Figure 3: Time trends in police size in Europe

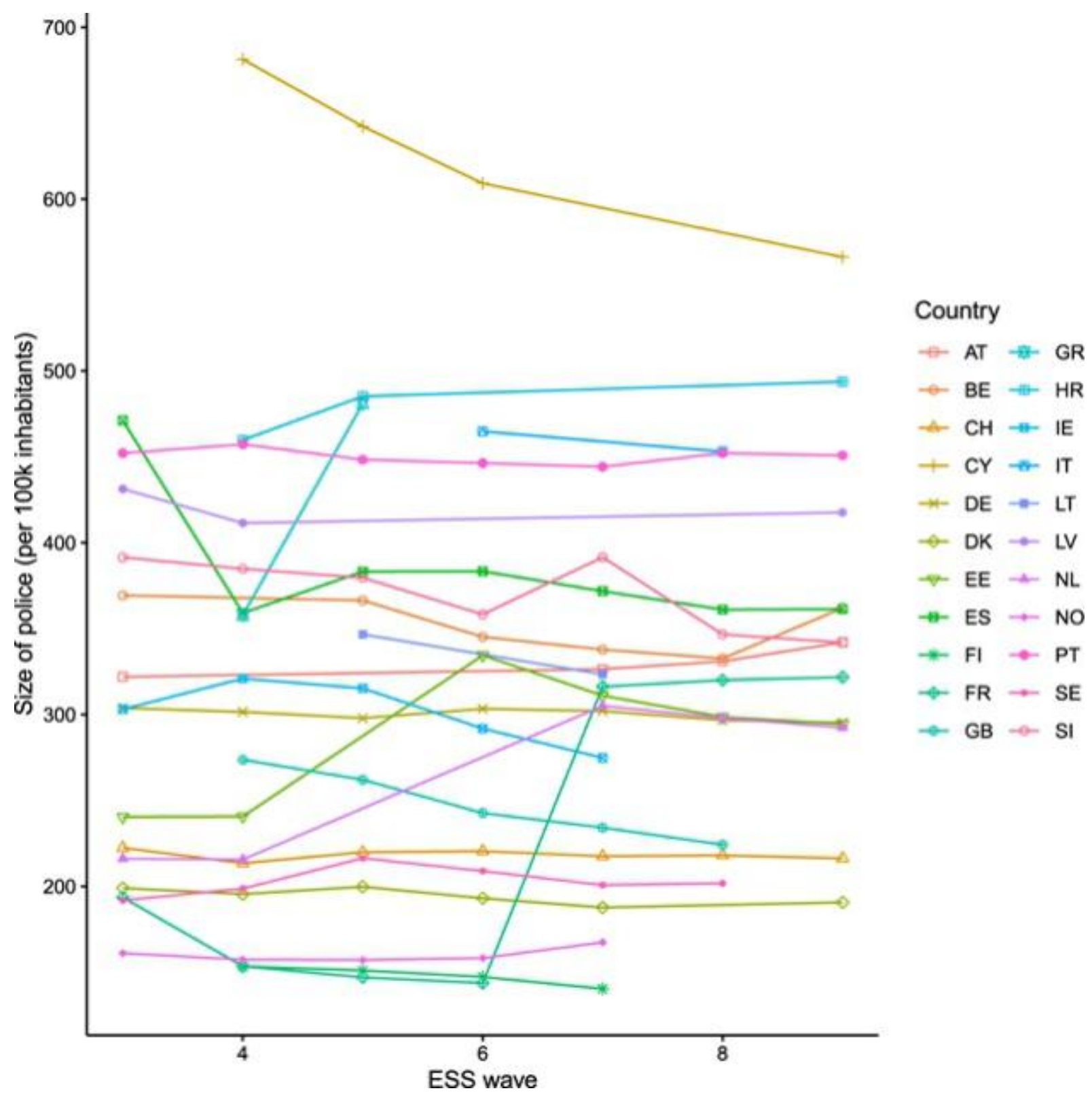

In short, descriptive findings suggest that, on the one hand, more police strongly correlates with low levels of trust among immigrants. On the other hand, police force size is rather time-invariant for most countries in the period of investigation, while trust in the police tends to have grown over time. Next, we try to explain these descriptive findings using random effects models.

\section{Random Effects Models}

The null model reveals that, while most variation is on the individual level, there is also some cross-national variation in immigrants' trust in the police. About ten percent of the total variance of police trust lies between countries, while about 88 percent is on the individual level. In comparison, immigrants' average trust in the police in a country is rather stable over time, with just over two percent of the total variance of trust being on the country-year level. While such patterns are not uncommon in longitudinal cross-national studies on public attitudes (Czymara 2021), this is particularly interesting as we cover a time span over 17 years, including several external shocks, such as the global financial crisis of 2008 or the refugee influx in 2015 . Moreover, it is worth noting that even little changes in trust over time can have an impact on public opinion (Mitchell 2021). 
We argued that experiences in migrants' origin countries are important as frames of reference and the larger the differences between institutions in origin and destination countries are, the stronger the effect on trust should be. However, as such reference frames tend to fade with time, this effect should be particularly strong for those who migrated recently. Figure 4 shows exactly that (also see the second column of Table 3). Recent immigrants (black line) who experienced strong institutional improvement though their migration have a predicted trust value of above 8 . In contrast, those who recently migrated to a country that is performing worse regarding rule of law than the origin country hold predicted values of less than 7 . Predicted trust levels of those who migrated a long time ago, though, are independent of institutional improvement (flat grey line). The difference in slopes between both lines is clearly statistically significant $(p<0.001)$. The empirical results strongly support both the Institutional Improvement-Hypothesis as well as the Fading Reference-Hypothesis. Strikingly, predicted trust values of those who migrated long ago are even lower than the trust values of those who moved to a country with less rule of law than the origin country. To explain this finding, we turn to the effects of discrimination.

Figure 4: Effect of institutional improvement conditional on time since migration

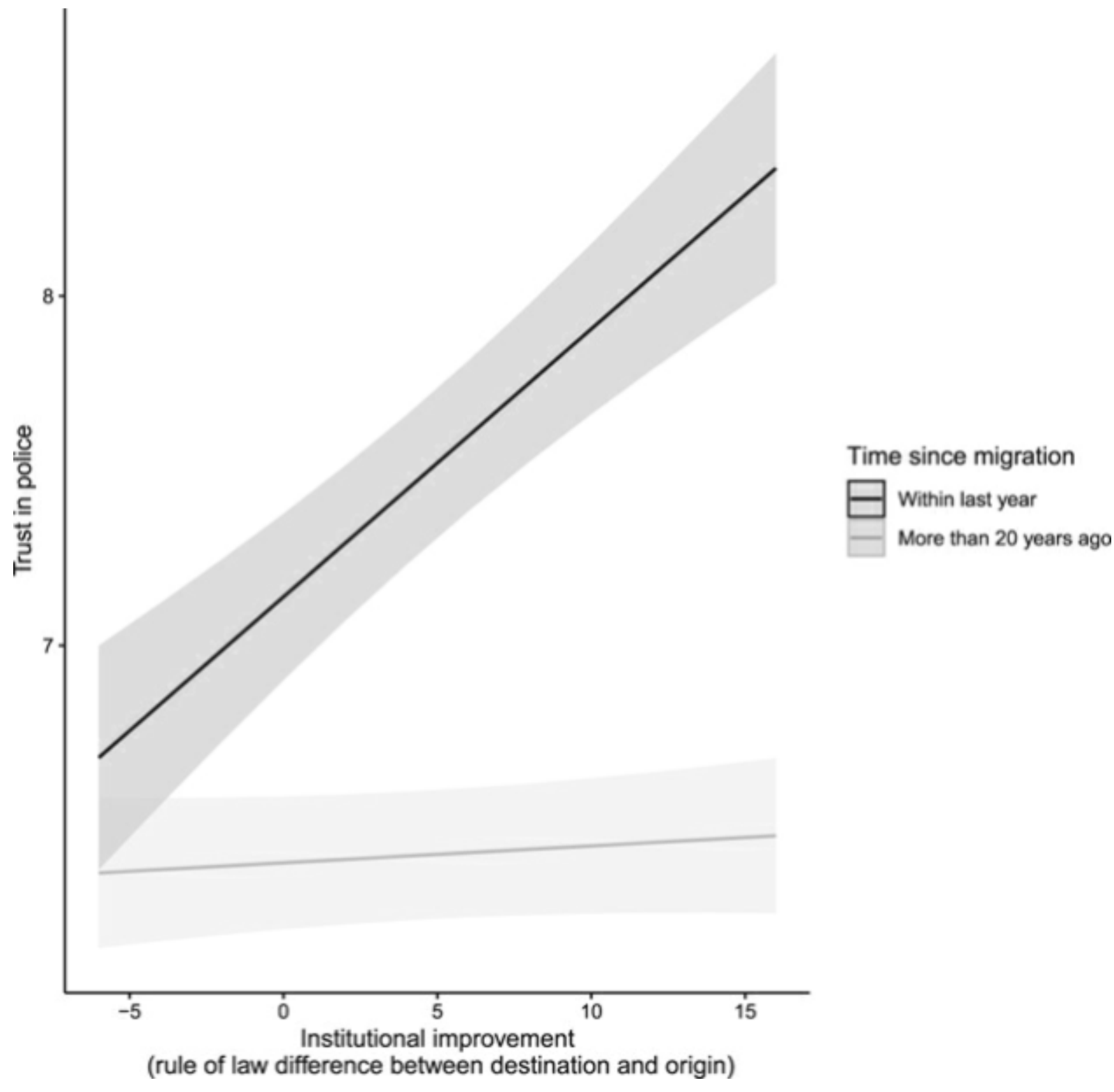

As we see in Figure 5, immigrants who report belonging to a discriminated-against group in their host country generally trust the police less (also see the third column of Table 3). While this does not unambiguously follow 
from the analysis, it seems that those who are generally more likely to be discriminated against are also more likely to be discriminated against by the police (Tyler 2005; Weitzer and Tuch 2005). However, Figure 5 also shows that the effect of discrimination on trust is stronger for those who immigrated a long time ago (grey) than for those who have migrated recently (black). For those who have immigrated within the last year, the effect of discrimination is $-0.5(p<0.001)$. For those who immigrated more than 20 years ago, the effect of discrimination amounts to $-0.9(p<0.001)$. This difference is statistically significant $(p=0.013)$. Put differently, those who have lived in a country for a long time and report belonging to a discriminated-against group trust the police least. A possible explanation of this result is that those who have stayed for a long time in a country have had more time to accumulate negative experiences with the police. As a result, they might show particularly low levels of trust. As an alternative test of this idea, we estimated the effect of being an ethnic minority member conditional on time since migration (see the last column of Table 3). One might think that belonging to an ethnic minority and belonging to a discriminated-against group should largely overlap. Interestingly, however, the correlation between both variables is only modest $(r=0.28)$. This being said, we see a similar picture regarding police trust: ethnic minority members trust the police less when they have stayed in the host country longer (notably even though recently migrated ethnic minority members trust the police more than non-minority members, as the main effect of the minority variable in Table 3 shows). The interaction of time since migration and being discriminated against is just as large as the interaction of time since migration and being a minority member (about -0.10). ${ }^{7}$ This is in line with our Discrimination Accumulation-Hypothesis.

\footnotetext{
${ }^{7}$ Note that estimating the effects of discrimination and minority status in the same model might lead to overcontrol bias. As the correlation between both variables is not very large, results are very similar when we exclude the respective other variable from the model (discrimination interaction $=-0.1, p=0.012$; minority interaction $=-0.12, p=0.001$ ).
} 
Figure 5: Discrimination effect conditional on time since migration

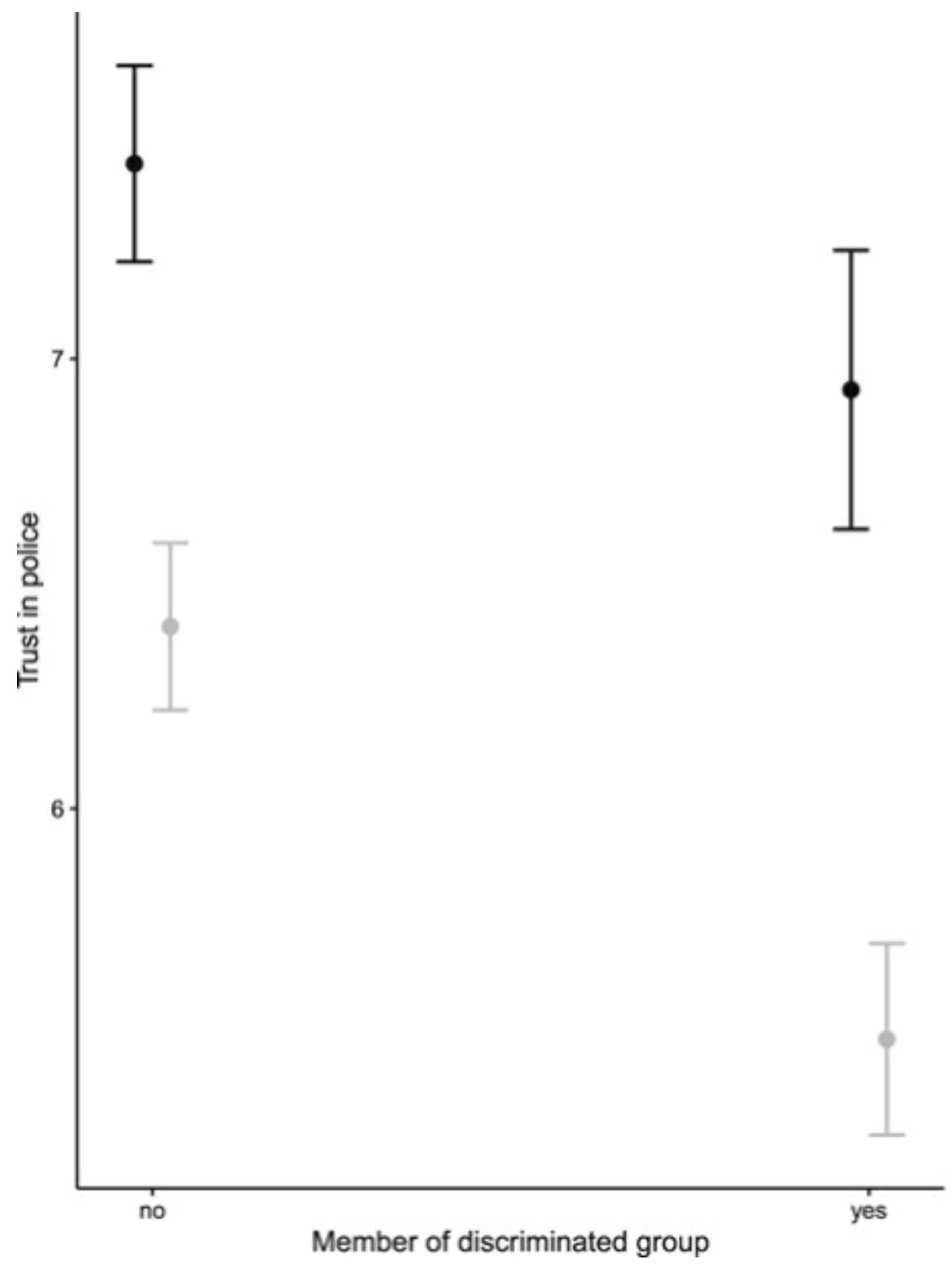

Time since migration

Within last year

More than 20 years ago

Table 3: Individual-level predictors of immigrants' trust in the police conditional on time since migration

\begin{tabular}{lccc}
\hline \hline Variables & $\begin{array}{c}\text { Institutional } \\
\text { Improvement } \\
\text { Estimates }\end{array}$ & $\begin{array}{c}\text { Discrimination } \\
\text { experience } \\
\text { Estimates }\end{array}$ & $\begin{array}{c}\text { Being ethnic } \\
\text { minority }\end{array}$ \\
\hline Institutional & $0.08^{* * *}$ & $0.02^{* * *}$ & $0.02^{* * *}$ \\
improvement & $(0.01)$ & $(0.00)$ & $(0.00)$ \\
Discrimination & $-0.82^{* * *}$ & $-0.50^{* * *}$ & $-0.81^{* * *}$ \\
experience & $(0.05)$ & $(0.14)$ & $(0.05)$ \\
Being ethnic & 0.06 & 0.07 & $0.37^{* *}$ \\
minority & $(0.04)$ & $(0.04)$ & $(0.11)$ \\
Time since & $-0.19^{* * *}$ & $-0.26^{* * *}$ & $-0.25^{* * *}$ \\
migration & $(0.03)$ & $(0.02)$ & $(0.02)$ \\
Institutional & $-0.02^{* * *}$ & & \\
improvement $X$ & & &
\end{tabular}




\begin{tabular}{|c|c|c|c|}
\hline \multirow{2}{*}{$\begin{array}{l}\text { Time since } \\
\text { migration } \\
\text { Discrimination } \\
X \text { Time since } \\
\text { migration }\end{array}$} & $(0.00)$ & & \\
\hline & \multicolumn{3}{|c|}{$-0.10^{*}$} \\
\hline & \multicolumn{3}{|c|}{$(0.04)$} \\
\hline \multirow{2}{*}{$\begin{array}{l}\text { Minority X Time } \\
\text { since migration }\end{array}$} & & & $-0.10^{* *}$ \\
\hline & & & $(0.03)$ \\
\hline $\begin{array}{l}\text { Control } \\
\text { variables }\end{array}$ & $\checkmark$ & $\checkmark$ & $\checkmark$ \\
\hline \multicolumn{4}{|l|}{ Random Effects } \\
\hline$\sigma^{2}$ & 5.42 & 5.42 & 5.42 \\
\hline \multirow[t]{2}{*}{$\tau_{00}$} & 0.08 essround:cntry & 0.08 essround:cntry & 0.08 essround:cntry \\
\hline & 0.12 cntry & 0.12 cntry & 0.12 cntry \\
\hline ICC & 0.04 & 0.04 & 0.04 \\
\hline $\mathrm{N}$ (countries) & 22 & 22 & 22 \\
\hline $\begin{array}{l}\mathrm{N} \text { (country- } \\
\text { waves) }\end{array}$ & 110 & 110 & 110 \\
\hline $\mathrm{N}$ (respondents) & 19147 & 19147 & 19147 \\
\hline AIC & 87.091 .330 & 87.106 .824 & 87.105 .116 \\
\hline
\end{tabular}

The evidence so far points to two processes that shape immigrants' trust: references to conditions in origin countries and potential discrimination experiences. The former leads new immigrants to hold a very positive view of the police of their new host country, especially if they have experienced institutional improvement. However, this positive effect fades over time, as the origin reference becomes less relevant. Simultaneously, the more time immigrants have spent in a country, the more discrimination experiences they can have accumulated. Hence, the effects of discrimination become stronger for long-term immigrants. A potential explanation for this finding is that opportunities for negative encounters with police become more likely with time since migration. To test this idea, we now turn to the effects on the country level.

Table 4: Police force size and immigrants' trust in the police

\begin{tabular}{lcccc}
\hline \hline & Police size & $\begin{array}{c}\text { Country } \\
\text { controls }\end{array}$ & $\begin{array}{c}\text { Individual } \\
\text { controls }\end{array}$ & Interaction \\
Variables & Estimates & Estimates & Estimates & Estimates \\
\hline Police size & 0.0009 & 0.0007 & 0.0006 & -0.0093 \\
$($ WE) & $(0.0014)$ & $(0.0012)$ & $(0.0012)$ & $(0.0087)$ \\
Police size & $-0.0048^{* * *}$ & $-0.0032^{*}$ & -0.0028 & $-0.0036^{*}$ \\
(BE) & $(0.0010)$ & $(0.0016)$ & $(0.0016)$ & $(0.0015)$ \\
Time since & & & $-0.2743^{* * *}$ & -0.1719 \\
migration & & & $(0.0195)$ & $(0.1179)$ \\
Police size & & & & 0.0006 \\
(WE) X Time & & & & \\
since & & & \\
migration & & & & $(0.0007)$
\end{tabular}


Police size

(BE) $X$ Time

since

migration

Police size

$-0.0004$

(WE) X Time

since

migration

(BE)

(0.0004)

Country-level

controls

Individual-

level controls

\section{Random Effects}

$\begin{array}{lllll}\sigma^{2} & 5.61 & 5.61 & 5.43 & 5.40 \\ \tau_{00} & 0.15 \text { essround:cntry } & 0.08 \text { essround:cntry } & 0.08 \text { essround:cntry } & 0.12 \text { essround:cntry } \\ & & & \\ & 0.26 \text { cntry } & 0.12 \text { cntry } & 0.12 \text { cntry } & 0.08 \text { cntry } \\ \tau_{11} & & & 0.01 \text { essround:cntry.livecnty_comb1 }\end{array}$

0.02 cntry.livecnty_comb1

$\rho_{01}$

-0.71 essround:cntry

\begin{tabular}{llllll} 
& & & \multicolumn{3}{l}{-0.58 cntry } \\
ICC & 0.07 & 0.03 & 0.04 & 0.04 & \\
$\mathrm{~N}$ & 7 essround & 7 essround & 7 essround & 7 essround \\
& 22 cntry & 22 cntry & 22 cntry & 22 cntry \\
\hline N (countries) & 22 & 22 & 22 & 22 \\
N (country- & 110 & 110 & 110 & & 110 \\
waves) & 19147 & 19147 & 19147 & 19147 & \\
N & & & & & \\
(respondents) & 87.623 .494 & 87.663 .511 & 87.106 .530 & 87.123 .478 \\
AIC & & & & & \\
\hline \hline
\end{tabular}

${ }^{*} p<0.05 * * p<0.01 \quad * * * p<0.001$

The BE in the first model in Table 4 confirms that police numbers have a negative association with police trust among immigrants: one more police officer per 100,000 inhabitants decreases immigrants' trust by 0.005 . To put things into perspective, this implies that one standard deviation more police decreases trust by 0.18 standard deviations $(p<0.001)$. As the descriptive evidence suggested, however, the effect within countries over time is virtually zero. This means that we do not observe the same association based on within-country variation over time. However, this is likely due to the fact that we do not observe many increases in police numbers in the first place. Additional analyses testing for (non-)parallel trends of countries, which are available upon request, show that there are also no country-specific slopes of the WE of police size.

The second model of Table 4 adds the country-level control variables rule of law, immigration, GDP, and crime. The BE of police force size is reduced but remains statistically significant $(p=0.038)$. This means that, 
somewhat in contrast to the findings of Nägel and Vera (2021), the negative impact of police force size on public trust is not fully explained by crime or malfunctioning institutions. Even after accounting for differences in Rule of Law and crime rates between countries, it is still true that immigrants in countries with more police officers trust the police less. As one might expect, the null WE of police numbers remains zero when adding control variables. The third model of Table 4 adds control variables on the individual level. While the estimate of the $B E$ of police force size remains similar in size, it is no longer statistically significant the five percent level. Thus, while the association remains negative, we cannot rule out the possibility that is zero based on the final model, including all control variables. While more police is associated with less trust (BE) among immigrants in Europe, we cannot confirm that this is a causal effect in the sense that increasing police numbers within a country lowers trust (WE). Support for the Police Force Size-Hypothesis is hence limited.

Finally, we hypothesized that the size of the national police force has a stronger effect on immigrants who came to a country a long time ago because negative contact with the police in the host country is more likely. However, the results are ambiguous. As the left panel of Figure 6 shows, the WE of the police force size effect is slightly negative for those who migrated recently (negative slope of the black line), whereas it is almost zero for those who migrated a long time ago (flat light grey line). This is the opposite of what we theoretically predicted, but the difference in the slopes between the two lines is not statistically significant $(p=0.384) .{ }^{8}$ Since our results indicate that long-term differences are more important than short-term changes, the right panel of Figure 6 plots the interaction of the BE of police force size and time since migration. Here we see that the association of police size and trust is negative for those who have migrated recently as well as for those who migrated more than 20 years ago. However, the size of the BE again does not depend on the time since migration, as the two lines are practically parallel. Put differently, the BE interaction is not statistically significant $(p=0.308)$. Thus, the results refute our Police Force Size Interaction Effect-Hypothesis. Yet, the model predicts the lowest level of trust in the police for immigrants who have stayed in a country with a large police force for a long time. A hypothetical immigrant, who came over 20 years ago to a country with 600 police officers per 100,000 inhabitants (which roughly corresponds to Cyprus), holds a predicted trust value of less than 5 out of 10 . In contrast, an immigrant who came to a country with 150 police officers per 100,000 (corresponding to Finland) in the past year, but who is otherwise identical, has a predicted value of more than 8 . This is a remarkable difference, corresponding to more than one standard deviation of the outcome. However, it is not significantly higher than the sum of the time since migration effect and the police size BE.

\footnotetext{
${ }^{8}$ As an alternative test, we re-ran the models including natives as well as first- and second-generation immigrants. These results replicate Röder and Mühlau (2012): first-generation immigrants trust the police more than natives, second-generation immigrants trust the police less than natives (both with $p<0.01$ ). However, there is no statistically significant interaction between immigrant status and national police force size.
} 
Figure 6: WE and BE of police size conditional on time since migration
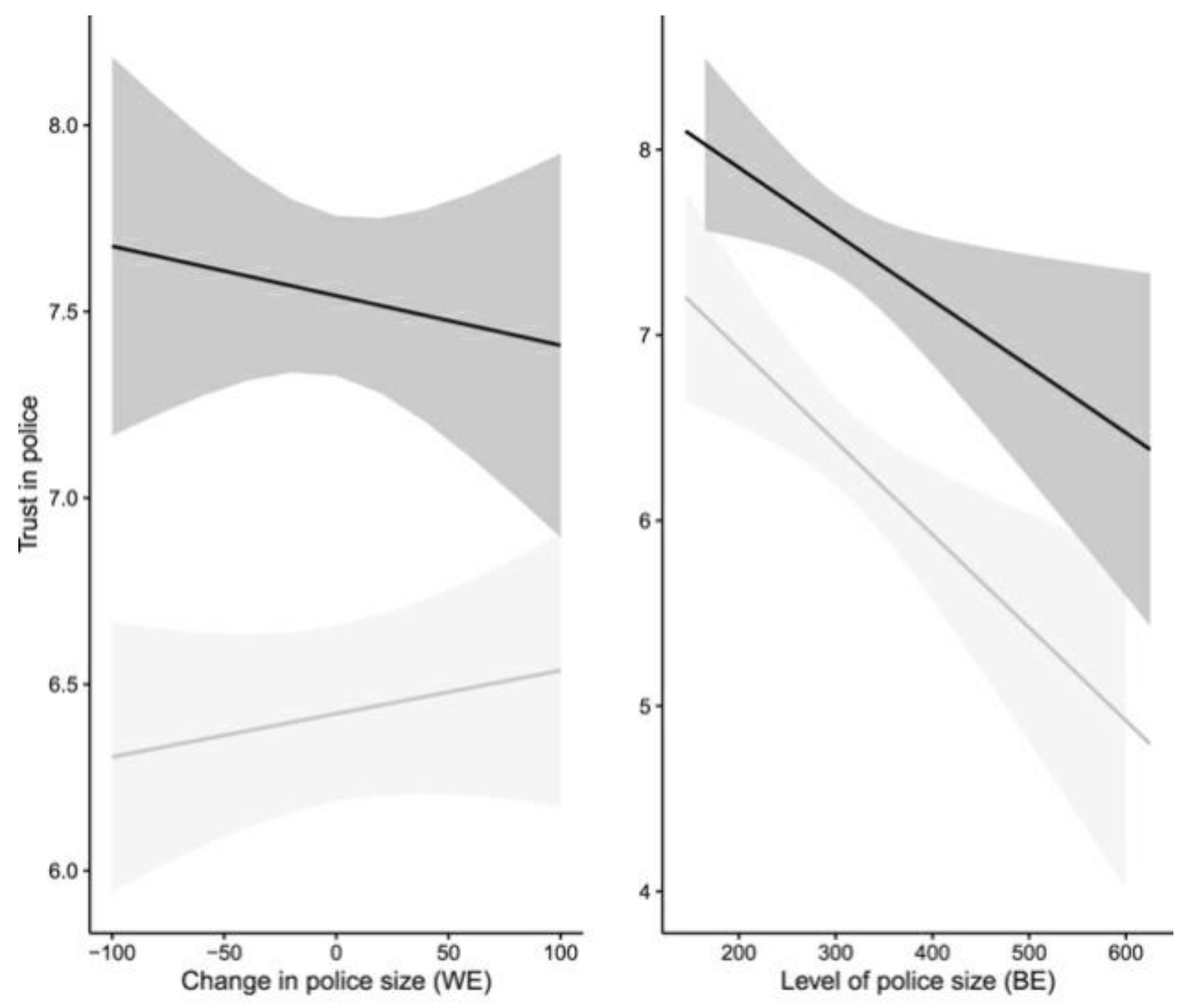

Time since migration

Within last year

More than 20 years ago

\section{Conclusion}

Our results provide support for both the cultural and experiential explanations of trust in the police. First, the analysis suggests immigration initially leads immigrants to trust the police in host countries more. This is especially true if they have experienced institutional improvement (i.e., came from a country where rule of law was lower). References to a more malfunctioning justice system seem, in many cases, to be the reason for more positive attitudes of immigrants compared to those of natives (Röder and Mühlau 2012). However, the more time immigrants spend in their host countries, the more this "honeymoon effect" vanishes and is in fact replaced by a discrimination effect that accumulates with length of stay. A possible explanation for this finding is that the longer immigrants have stayed in their destination country, the more likely they are to have negative encounters with police, especially when they belong to an ethnic minority (Tyler 2005; Weitzer and Tuch 2005). In this case, the experiences that immigrants have over time overwrite their cultural expectations for their host country in comparison to their home countries. Both processes - fading origin effects and negative police contact - in tandem result in an erosion of the initially-high levels of trust in the police among immigrants in Europe.

Regarding cross-national differences and the role of national police force size, we find that immigrants in countries with more police relative to the population trust the police less, on average. Accounting for 
differences in crime, rule of law indicators, immigration, and GDP reduces the size of this association but does not eliminate it, which is somewhat in contrast to Nägel and Vera (2021). A possible explanation for this discrepancy in findings is the central role that negative contact plays in the erosion of trust in the police. While we expected the relationship between trust and police size to be dependent on an immigrant's time since migration to a host country, the data did not confirm this. This suggests that the effect size of police force size on trust in the police is consistent regardless of whether people have recently immigrated or been in a host country for a long time. Additional analyses show that the association between police force size and trust is also similarly large for natives and second-generation immigrants as compared to first-generation immigrants. Similarly, the fact that police force size is mostly time-invariant for the countries and period we investigate leads to a null effect of changes in the police force size. On a conceptual note, Bell, Fairbrother, and Jones (2019) argued: "Social science is concerned with understanding the world as it exists, not just dynamic changes within it. [...] We take it as axiomatic that we need both micro and macro associations to understand the whole of 'what is going on'." (1053). We believe that this perfectly describes our situation. The fact that we do not observe much fluctuation within our 13-year period does not render the differences that do exist between countries unimportant.

The fact that the police force size BE does not depend on individual migration status or on time since migration further boosts the impression that there seems to be some other relevant factor, such as the type of policing, militarization of police forces, or mass media framing of police actions (Nägel and Lutter 2021). Unfortunately, reliable measures of policing are scarce to nonexistent. Our need for such variables for many countries and a large time span complicates this issue further. Future research may want to shed more light on this. For now, we conclude that the association between police force size does not seem to depend on the time since migration and neither does police force size seem to have an effect particularly on immigrants' trust vis-àvis that of natives. At the same time, immigrants who report belonging to a discriminated-against group trust the police least when they have spent a significant amount of time in the host country. While we attribute this to the accumulation of opportunities to experience discrimination, recent research on discrimination experiences suggests that, as immigrants spend more time in their host country, they become more aware of their differential treatment and therefore are more likely to perceive discrimination when it is occurring (Diehl et al.2021), presenting an integration paradox. However, Diehl and colleagues also point out that this "by no means implies that perceived discrimination is detached from reality" (1). In either case, time remains an important moderator. Our testing of discrimination effects remains somewhat indirect as, unfortunately, there is no item in all ESS waves that measures negative contact or discrimination experiences with police directly. It is likely that groups who are generally being discriminated against are also being discriminated against by police. Moreover, we ultimately cannot test our assumption that there is negative contact with the police. We view this assumption as generally plausible and in line with prior research (Bradford and Jackson 2018; Tyler 2005), as we have outlined above. Given that governments that perform particularly badly in this respect have the strongest incentives not to collect such data, we are not very optimistic that this statistical cavity will be filled any time soon. Another limitation of our study is that the ESS is not primarily designed to analyze immigrants. Perhaps most problematically in this respect is that the questionnaire is only distributed in the language of the respective host country. This implies that new or less-integrated immigrants are less likely to participate due to language barriers. These immigrants are also more likely to be ethnic minorities in these countries. The systematic lack of such immigrants in our data should lead to an underestimation of the effects of negative encounters with police. Finally, we used the rule of law value for origin countries at the time of the interview and not the time of migration, which might be problematic if there is strong temporal fluctuation in rule of law within origin countries. Unfortunately, the rule of law data are only available from 2006 onward. This does not allow for the inclusion of long-time immigrants (and neither for the inclusion of the first two ESS waves). In addition, the ESS only asks the particular year of migration since wave five. We thus use the value of the origin country at the year of the interview as a proxy.

Since trust is a valuable thing that can assist the police in their jobs and prompt vulnerable groups to seek help when they have been the victims of crime, we see the results of our analysis as a missed opportunity. 
Recent research by Schnaudt et al. (2021) suggests that individuals' institutional trust is directed at the parts of the state that are charged with enacting regulations (i.e. the police). In a similar vein, our findings suggest that if countries wish to increase trust in the police, it would appear that the strategy of increasing institutional capacity by hiring more police might serve to have the opposite effect. In contrast, high levels of trust in the police should instead be preserved among new immigrants and restored amongst those who have lived in their host countries for a long time. One way to reduce the discrimination experiences of immigrants should be to refine procedural justice practices.

\section{Acknowledgements}

Earlier versions of the paper were presented at the 2021 meeting of the European Consortium for Sociological Research, the IAB-ECSR Interdisciplinary Conference "Refugee Migration and Integration Revisited: Lessons from the Recent Past", the Research Seminar at Umeå University, and the Colloquium Empirical Social Research at the University of Konstanz. We thank all discussants and the anonymous reviewers for their very helpful comments and feedback, and Subin Chang for proofreading.

\section{References}

Bates, Douglas, Martin Mächler, Ben Bolker, and Steve Walker. 2015. “Fitting Linear Mixed-Effects Models Using \{lme4\}."Journal of Statistical Software 67 (1): 1-48. doi:10.18637/jss.v067.i01.

Bell, Andrew, Malcolm Fairbrother, and Kelvyn Jones. 2019. "Fixed and Random Effects Models: Making an Informed Choice." Quality and Quantity 53 (2): 1051-1074. doi:10.1007/s11135-018-0802-x.

Bradford, Ben, and Jonathan Jackson. 2018. "Police Legitimacy among Immigrants in Europe: Institutional Frames and Group Position." European Journal of Criminology 15 (5): 567-588.

Cimentada, Jorge. 2019. Download Data from the European Social Survey on the Fly.

Czymara, Christian S. 2021. "Attitudes Toward Refugees in Contemporary Europe: A Longitudinal Perspective on Cross-National Differences." Social Forces 99 (3): 1306-1333. doi:10.1093/sf/soaa055.

Czymara, Christian S., and Marcus Eisentraut. 2020. "A Threat to the Occident ? Comparing Human Values of Muslim Immigrants, Christian, and Non-Religious Natives in Western Europe." Frontiers in Sociology 5: 1-15. doi:10.3389/fsoc.2020.538926.

Dahlberg, Stefan, and Jonas Linde. 2018. "Socialization or Experience? Institutional Trust and Satisfaction with Democracy among Emigrants in Different Institutional Settings." Journal of Politics 80 (4): 1389-1393. doi:10.1086/698661.

Diehl, Claudia, Elisabeth Liebau, and Peter Mühlau. 2021. “How Often Have You Felt Disadvantaged? Explaining Perceived Discrimination." KZfSS Kölner Zeitschrift Für Soziologie Und Sozialpsychologie, May, 1-24. doi:10.1007/s11577-021-00738-y.

Dinesen, Peter Thisted. 2012. "Does Generalized (Dis)Trust Travel? Examining the Impact of Cultural Heritage and Destination-Country Environment on Trust of Immigrants." Psychology 33 (4): 495-511.

Fairbrother, Malcolm. 2014. "Two Multilevel Modeling Techniques for Analyzing Comparative Longitudinal Survey Datasets." Political Science Research and Methods 2 (1): 119-140. doi:10.1017/psrm.2013.24.

Giesselmann, Marco, and Alexander W. Schmidt-Catran. 2019. "Getting the within Estimator of Cross-Level Interactions in Multilevel Models with Pooled Cross-Sections: Why Country Dummies (Sometimes) Do Not Do the Job." Sociological Methodology 49 (1): 190-219. doi:10.1177/0081175018809150. 
Heisig, Jan Paul, and Merlin Schaeffer. 2019. "Why You Should Always Include a Random Slope for the LowerLevel Variable Involved in a Cross-Level Interaction." European Sociological Review 52 (2): 258-279. doi:10.1093/esr/jcy053.

Kääriäinen, Juha Tapio. 2007. "Trust in the Police in 16 European Countries: A Multilevel Analysis." European Journal of Criminology 4 (4): 409-435. doi:10.1177/1477370807080720.

Kääriäinen, J. 2016. “Why Trust in the Police Varies Between European Countries.” European Law Enforcement Research Bulletin 1: 91-100

Kainu, Markus. 2020. Rqog: Download Data from the Quality of Government Institute Data.

Kropko, Jonathan, and Robert Kubinec. 2020. "Interpretation and Identification of Within-Unit and CrossSectional Variation in Panel Data Models." PLOS ONE 15 (4): 1-22.

Lahti, Leo, Janne Huovari, Markus Kainu, and Przemyslaw Biecek. 2017. Eurostat R Package. Vol. 9.[Q15]

Lee, Yong Jei, John E. Eck, and Nicholas Corsaro. 2016. "Conclusions from the History of Research into the Effects of Police Force Size on Crime-1968 through 2013: A Historical Systematic Review." Journal of Experimental Criminology 12: 431-451. doi:10.1007/s11292-016-9269-8.

Lüdecke, Daniel. 2019. SjPlot: Data Visualization for Statistics in Social Science.

Lüdecke, Daniel, Mattan S. Ben-Shachar, Indrajeet Patil, and Dominique Makowski. 2020. "Parameters: Extracting, Computing and Exploring the Parameters of Statistical Models Using R." Journal of Open Source Software 5 (53): 2445. doi:10.21105/joss.02445.

Mewes, Jan, Malcolm Fairbrother, Giuseppe Nicola Giordano, Cary Wu, and Rima Wilkes. 2021. "Experiences Matter: A Longitudinal Study of Individual-Level Sources of Declining Social Trust in the United States." Social Science Research 95: 102537. doi:10.1016/j.ssresearch.2021.102537.

Mishler, William, and Richard Rose. 2001. "What Are the Origins of Political Trust? Testing Institutional and Cultural Theories in Post-Communist Societies." Comparative Political Studies 34 (1): 30-62.

doi:10.1177/0010414001034001002.

Mitchell, Jeffrey. 2021. "Social Trust and Anti-Immigrant Attitudes in Europe: A Longitudinal Multi-Level Analysis." Frontiers in Sociology 6: 604884. doi:10.3389/fsoc.2021.604884.

Nägel, Christof, and Mark Lutter. 2021. "The 2017 French Riots and Trust in the Police: A Quasi-Experimental Approach." European Journal of Criminology, 1-22.

Nägel, Christof, and Antonio Vera. 2021. "More Cops, Less Trust? Disentangling the Relationship Between Police Numbers and Trust in the Police in the European Union." Policing: A Journal of Policy and Practice 15 (2): 939-949. doi:10.1093/police/paaa098.

Resh, Nura. 2018. "Sense of Justice in School and Social and Institutional Trust." Comparative Sociology 17 (34): 369-385. Brill Academic Publishers. doi:10.1163/15691330-12341465.

Röder, Antje, and Peter Mühlau. 2012. "What Determines the Trust of Immigrants in Criminal Justice Institutions in Europe?” European Journal of Criminology 9 (4): 370-387. doi:10.1177/1477370812447265.

Rothstein, Bo, and Dietlind Stolle. 2008. "The State and Social Capital: An Institutional Theory of Generalized Trust." Comparative Politics 40 (4): 441-459.

Schaap, D. 2020. "Citizens' Trust in the Police and Police Trust-Building Strategies." European Law Enforcement Research Bulletin 19: 27-37.

Schmidt-Catran, Alexander W., and Malcolm Fairbrother. 2016. "The Random Effects in Multilevel Models: Getting Them Wrong and Getting Them Right." European Sociological Review 32 (1): 23-38. doi:10.1093/esr/jcv090. 
Schnaudt, Christian, Caroline Hahn, and Elias Heppner. 2021. "Distributive and Procedural Justice and Political Trust in Europe." Frontiers in Political Science 3: 24. doi:10.3389/fpos.2021.642232.

Tyler, Tom R. 2005. "Policing in Black and White: Ethnic Group Differences in Trust and Confidence in the Police." Police Quarterly 8 (3): 322-342. doi:10.1177/1098611104271105.

Van Mol, C., and H. de Valk. 2016. "Migration and Immigrants in Europe: A Historical and Demographic Perspective." In Integration Processes and Policies in Europe. IMISCOE Research Series, edited by B. GarcésMascareñas, and R. Penninx, 31-66. Cham: Springer.

Weitzer, Ronald, and Steven A. Tuch. 2005. "Determinants of Public Satisfaction with the Police." Police Quarterly 8 (3): 279-297. doi:10.1177/1098611104271106.

Yeager, David S, Valerie Purdie-Vaughns, Sophia Yang Hooper, and Geoffrey L Cohen. 2017. “Loss of Institutional Trust Among Racial and Ethnic Minority Adolescents: A Consequence of Procedural Injustice and a Cause of Life-Span Outcomes." Child Development 88 (2): 658-676. doi:10.1111/cdev.12697.

Ziller, Conrad. 2017. "Equal Treatment Regulations and Ethnic Minority Social Trust." European Sociological Review 33 (4): 563-575. doi:10.1093/esr/jcx059.

Ziller, Conrad, and Christoph Spörlein. 2020. "Residential Segregation and Social Trust of Immigrants and Natives: Evidence from the Netherlands." Frontiers in Sociology 5: 45. doi:10.3389/fsoc.2020.00045 


\section{Appendix}

Figure A1: Trends in GDP

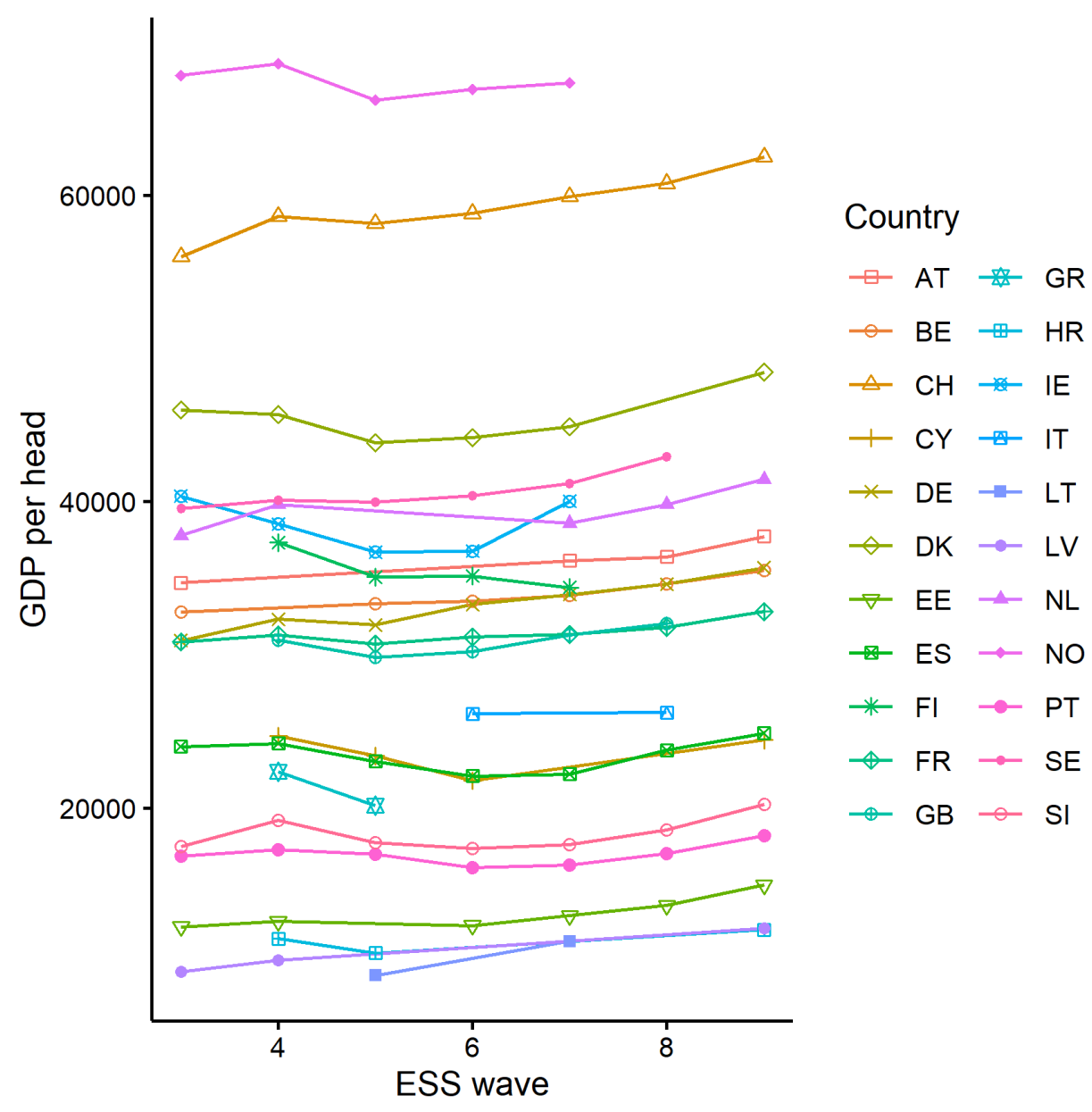


Figure A2: Trends in crime

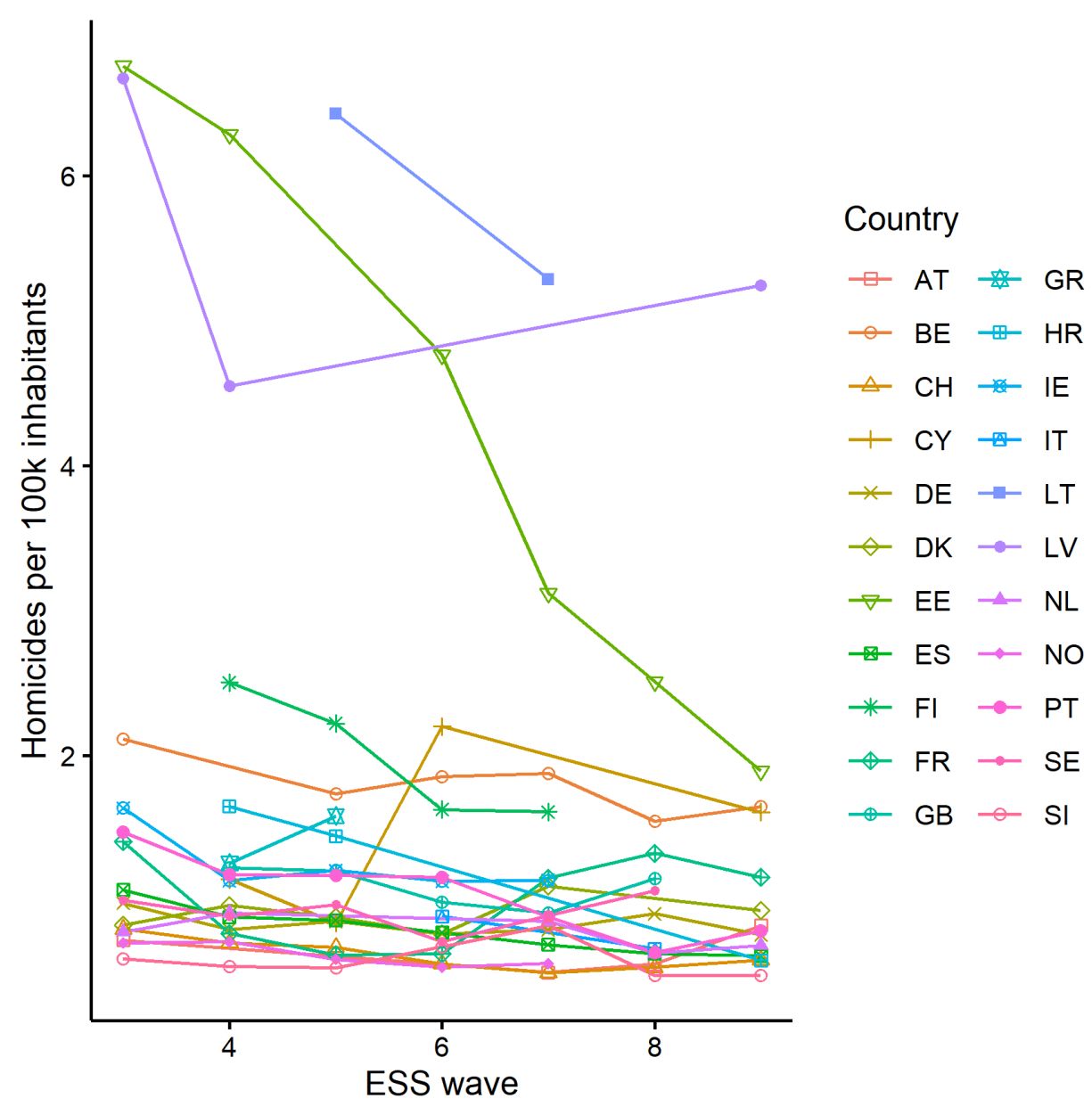


Figure A3: Trends in rule of law

\begin{tabular}{|c|c|c|c|c|c|c|c|}
\hline & \multicolumn{7}{|c|}{ ESS wave } \\
\hline & 3 & 4 & 5 & 6 & 7 & 8 & 9 \\
\hline AT & 15 & & & & 15 & 15 & 15 \\
\hline $\mathrm{BE}$ & 15 & & 15 & 15 & 15 & 13 & 15 \\
\hline $\mathrm{CH}$ & 15 & 15 & 15 & 15 & 15 & 15 & 15 \\
\hline $\mathrm{CY}$ & & 15 & 15 & 15 & & & 15 \\
\hline $\mathrm{DE}$ & 15 & 15 & 15 & 15 & 15 & 14 & 14 \\
\hline DK & 15 & 14 & 14 & 15 & 15 & & 14 \\
\hline $\mathrm{EE}$ & 14 & 14 & & 14 & 14 & 14 & 14 \\
\hline ES & 14 & 14 & 14 & 14 & 15 & 15 & 15 \\
\hline $\mathrm{FI}$ & & 16 & 16 & 16 & 16 & & \\
\hline FR & 14 & 15 & 14 & 15 & 15 & 13 & 13 \\
\hline GB & & 14 & 15 & 15 & 15 & 14 & \\
\hline GR & & 12 & 11 & & & & \\
\hline $\mathrm{HR}$ & & 10 & 11 & & & & 11 \\
\hline $\mathrm{IE}$ & 15 & 15 & 15 & 15 & 15 & & \\
\hline IT & & & & 12 & & 12 & \\
\hline LT & & & 13 & & 13 & & \\
\hline LV & 12 & 12 & & & & & 12 \\
\hline $\mathrm{NL}$ & 15 & 15 & & & 15 & 15 & 15 \\
\hline NO & 16 & 16 & 16 & 16 & 16 & & \\
\hline PT & 15 & 15 & 15 & 15 & 15 & 15 & 14 \\
\hline SE & 16 & 16 & 16 & 16 & 16 & 16 & \\
\hline SI & 14 & 14 & 14 & 14 & 14 & 14 & 15 \\
\hline
\end{tabular}

